\title{
Trama burocrática y documentos secretos. Dispositivos 'legales' para la represión de los trabajadores de la administración pública de Córdoba (1974-1978) ${ }^{1}$
}

\section{Bureaucratic plot and secret documents. 'Legal' devices for the repression of workers in the public administration of Córdoba (1974-1978)}

Silvia Romano ${ }^{2}$

\section{Resumen}

Este trabajo continúa la indagación sobre prácticas burocráticas orientadas al disciplinamiento y la represión de los trabajadores de la administración pública de Córdoba en el período que transcurre entre el golpe policial, conocido como «Navarrazo», que destituyó al gobernador y vicegobernador $(28$ de febrero 1974) y los tres primeros años de la dictadura instaurada por el Proceso de Reorganización Nacional (PRN, 24 de marzo 1976). En ese período se aplicaron diversos dispositivos, como la ley de prescindibilidad y el Estatuto del Empleado Público (1974) que se solaparon luego con «leyes de facto» dictadas durante el PRN, tales como la 5911 y 5913 (1976, baja por razones de seguridad y prescindibilidad, respectivamente) con el propósito de «depurar» la administración pública. La arbitrarie-

\section{Abstract}

This work continues the investigation of bureaucratic practices aimed at disciplining and repressing the workers of the Córdoba public administration in the period between the police coup, known as «Navarrazo», which removed the governor and deputy governor (February 28, 1974 ) and the first three years of the dictatorship established by the National Reorganization Process (PRN, March 24, 1976). During this period, various provisions were applied, such as the expendable law and the Public Employee Statute (1974) that later overlapped with «de facto laws» passed during the PRN, such as 5911 and 5913 (1976, down for reasons of security and expendability, respectively) with the purpose of «purifying» the public administration. The arbitrariness of the measures made use

${ }^{1}$ Trabajo recibido el 20/05/2020. Aceptado el 01/07/2020.

${ }^{2}$ Universidad Nacional de Córdoba. Contacto: silviaoromano@gmail.com 
dad de las medidas se sirvió de una profusa normativa y de prácticas rutinarias, burocráticas y legalistas, que coexistieron con la represión ilegal y el terrorismo de Estado, de lo que da cuenta el importante número de trabajadores desaparecidos y asesinados. En ese marco, haremos foco en dos aspectos vinculados a dichas prácticas: las cesantías y las renuncias de personal, que crecieron exponencialmente entre 1976 y 1978. Paralelamente, aportaremos nueva evidencia sobre la articulación estrecha entre las autoridades de facto, sus procedimientos burocrático-administrativos y los servicios de inteligencia para la persecución ideológica y la represión de los empleados públicos. Para ello recurrimos, entre otros, a «documentos secretos» custodiados en el Archivo de Gobierno de la Provincia de Córdoba.

Palabras clave: historia reciente; burocracia y represión; empleados públicos de Córdoba; terrorismo de estado; servicios de inteligencia of profuse regulations and routine, bureaucratic and legalistic practices, which coexisted with illegal repression and State terrorism, which is reflected in the significant number of missing and murdered workers. Within this framework, we will focus on two aspects related to said practices: layoffs and resignations of personnel, which grew exponentially between 1976 and 1978. At the same time, we will provide new evidence on the close coordination between de facto authorities, their bureaucratic-administrative procedures and the intelligence services for the ideological persecution and repression of public employees. For this we resort, among others, to «secret documents» kept in the Government Archive of the Province of Córdoba).

Keywords: recent history; bureaucracy and repression; public employees of Córdoba; State terrorism; intelligence services

\section{Presentación $^{3}$}

Este trabajo continúa y complementa la indagación que realizamos sobre prácticas burocráticas orientadas al disciplinamiento y la represión de los trabajadores de la administración pública de Córdoba en el período que transcurre entre el golpe policial, conocido como «Navarrazo» (28 de febrero 1974) que destituyó al gobernador y vicegobernador electos constitucionalmente y avalado por la intervención federal de la provincia y los tres primeros años de la dictadura instaurada por el Proceso de Reorganización Nacional (PRN, 24 de marzo 1976) (Roma-

\footnotetext{
${ }^{3}$ Una versión preliminar de este texto fue presentada en el Workshop Represión, Memoria y Burocracia en Argentina, organizado por el Instituto de Estudios Socio-Históricos y el Instituto de Estudios Históricos y Sociales de La Pampa CONICET/UNLPam, en Santa Rosa, La Pampa, 24 y 25 de octubre de 2019. Agradezco los comentarios de Roberto Pittaluga recibidos en esa ocasión.
} 
no, 2018). ${ }^{4}$ En ese período se aplicaron diversos dispositivos, ${ }^{5}$ como la ley de prescindibilidad y el Estatuto del Empleado Público (5719 de 1974) que luego se solaparon con «leyes de facto» dictadas durante el PRN, tales como la 5911 y 5913 (1976, baja por razones de seguridad, vinculación con actividades subversivas y disociadoras; y de prescindibilidad, respectivamente) con el propósito de «depurar», sancionar y cesantear a miles de empleados básicamente por razones políticas e ideológicas. La arbitrariedad de las medidas se sirvió de una profusa normativa y de prácticas rutinarias, burocráticas y argumentos legales, que coexistieron y se articularon con la represión ilegal y el terrorismo de Estado, como da cuenta el importante número de trabajadores que serían secuestrados, desaparecidos y asesinados clandestinamente. En ese marco, en esta ocasión nuestro análisis hará foco en dos aspectos vinculados a dichas prácticas: a) las cesantías o «bajas», según el eufemismo empleado, y b) las renuncias de personal, que crecieron exponencialmente entre $1976 \mathrm{y}$ 1978. Paralelamente, aportaremos nueva evidencia en relación a nuestra hipótesis de que hubo una articulación estrecha entre las autoridades provinciales de facto, sus procedimientos burocrático-administrativos y los servicios de inteligencia orientados a la persecución ideológica y la represión de los empleados públicos. Para ello recurrimos a «documen-

\footnotetext{
${ }^{4}$ Utilizo aquí -salvo en casos particulares- los términos trabajadores, empleados, agentes, etc. sin distinción de género a los fines de agilizar la lectura.

${ }^{5}$ Empleamos el término dispositivo según lo expuesto por Agamben (2006) en su revisión del significado que Foucault daba al mismo en distintos textos y que cita: «Lo que trato de indicar con este nombre es, en primer lugar, un conjunto resueltamente heterogéneo que incluye discursos, instituciones, instalaciones arquitectónicas, decisiones reglamentarias, leyes, medidas administrativas, enunciados científicos, proposiciones filosóficas, morales, filantrópicas, brevemente, lo dicho y también lo no-dicho, éstos son los elementos del dispositivo. El dispositivo mismo es la red que se establece entre estos elementos.»; «...por dispositivo, entiendo una especie -digamos- de formación que tuvo por función mayor responder a una emergencia en un determinado momento. El dispositivo tiene pues una función estratégica dominante... El dispositivo está siempre inscripto en un juego de poder»; «... es discursivo y no discursivo» (p.1). Por su parte, Agamben señala que llamará literalmente dispositivo «a cualquier cosa que tenga algún modo la capacidad de capturar, orientar, determinar, interceptar, modelar, controlar y asegurar los gestos, las conductas, las opiniones y discursos de los seres vivientes» (p. 3). Resulta también pertinente la síntesis que propone García Falno (2011): «Un dispositivo sería entonces un complejo haz de relaciones entre instituciones, sistemas de normas, formas de comportamiento, procesos económicos, sociales, técnicos y tipos de clasificación de sujetos, objetos y relaciones entre éstos, un juego de relaciones discursivas y no discursivas, de regularidades que rigen una dispersión cuyo soporte son prácticas» (p.3).
} 
tos secretos» conservados y ahora accesibles en el Archivo de Gobierno de la Provincia de Córdoba. Asimismo contamos con documentación procedente de los Servicios de Inteligencia del Estado (SIDE), empleados parcialmente en la primera parte de nuestro trabajo y algunos testimonios de ex agentes de la administración.

Esta propuesta se articula con el trabajo anterior en tanto se referencia en su marco teórico metodológico; en el estado de la cuestión, en la reconstrucción y el análisis del aparato «legal» producido y enuna parte de los datos construidos para esa investigación. ${ }^{6}$ En este sentido, el relevamiento de fuentes que realizamos en la actual etapa sobre despidos y renuncias ocurridos en 1977 y 1978, así como el de documentos secretos y de inteligencia nos permiten conformar el cuadro que nos planteamos delinear inicialmente en el proyecto de investigación y, en ese movimiento, ampliar la información sobre personas desaparecidas que se desempeñaron en la administración pública.

Resumimos a continuación algunos rasgos de los gobiernos de los sub períodos 1974-76 y 1976-78, dado su desarrollo en el marco de regímenes políticos diferentes así como parte de nuestro marco interpretativo. $^{7}$

Tras el levantamiento policial asumió interinamente la gobernación de Córdoba el presidente de la Cámara de Diputados Mario Dante Agodino, avalado por gobierno nacional y las autoridades del PJ. En los primeros días de marzo de 1974, el Congreso de la Nación aprobó el proyecto de intervención federal presentado por el presidente Perón que legitimaba la rebelión policial. Entre el 15 de marzo del '74 y el 24 de marzo del '76 se sucedieron tres interventores vinculados a la derecha peronista. En efecto, desde hacía tiempo sectores de la derecha políticosindical peronista venían desarrollando una ofensiva de «depuración ideo-

\footnotetext{
${ }^{6}$ En esa etapa trabajamos sobre resoluciones relativas a pedidos de licencia sin goce de haberes, pases de personal y sanciones varias de tres ministerios y/o reparticiones (Ministerio de Gobierno, Secretaría General de la Gobernación; y Cultura - Dirección General de Actividades Artísticas de la Provincia) para el período 1974-1978; toda la legislación producida en ese lapso y los Decretos del Poder Ejecutivo provincial para los años 1974-1976, donde registramos cesantías, «bajas», cese de funciones, designaciones dejadas sin efecto, rescisión de contratos, y renuncias. El corte a fines de 1976 se debió a la muy voluminosa masa documental producida por el gobierno de facto: 6.566 decretos sólo para ese año, mientras que en algo más de dos años del período anterior registramos un total de 470 decretos. Cf. Romano (2018).

${ }^{7}$ Lo que sigue resume parte de la introducción de nuestro trabajo Romano (2018). Cf. Bibliografía adjunta.
} 
lógica» y denunciando la infiltración marxista en Córdoba, «un foco de infección» que incluía al gobierno, la CGT, los sindicatos combativos y clasistas - principalmente Luz y Fuerza y SMATA- y, en suma, el estado de radicalización política y de movilización popular. ${ }^{8}$ El Brigadier $(\mathrm{R})$ Raúl Oscar Lacabanne, interventor entre el 07/09/74 el 19/09/75, fue quien desplegó la mayor represión legal e ilegal en el ámbito provincial y en la administración pública. ${ }^{9}$ Como es sabido, la intervención federal de Córdoba y las de otras provincias se inscribieron en el marco y fueron parte de, un proceso creciente de restricción de derechos y garantías constitucionales, sanción de leyes y decretos represivos contra la «subversión» y de control político e ideológico de amplio alcance que, finalmente, habilitaron a las Fuerzas Armadas a aniquilar (el accionar de) la «subversión» y a poner bajo su dependencia a las fuerzas de seguridad, lo que promovió la progresiva militarización del Estado y les permitió ensayar formas de represión y exterminio clandestinos que más tarde generalizarían a todo el territorio nacional. ${ }^{10}$ Así, lo excepcional de las medidas legales admitido por el propio orden jurídico profundizó el perfil autoritario represivo y la suspensión progresiva del Estado de Derecho en nombre de su preservación. ${ }^{11}$

Durante el período 1974-1976 ese perfil coexistió y se articuló con las «listas negras», las amenazas, los atentados, los secuestros y asesina-

\footnotetext{
${ }^{8}$ Sobre el tema véase Servetto (1998), Ortíz (2014).

${ }^{9}$ Lacabanne se atribuía la misión de realizar un «operativo de limpieza» en defensa de «un estilo de vida: la argentinidad», atacado por los «subversivos», calificación que incluía según él a «todo tipo de delincuente, sea de orden político, ideológico, económico o común», a «la guerrilla y la subversión», o bien a la izquierda en general. En otros pasajes destacaba que «ésta es una guerra real, donde hay bajas todos los días». Citado en Romano (2017 a).

${ }^{10}$ Véase en Servetto (2010) un análisis de las políticas de las intervenciones, sus alianzas y opositores.

${ }^{11}$ Sobre el tema Cf. Franco (2012); Pittaluga (2006); Paiaro (2014). Entre las numerosas disposiciones dictadas en este período conviene mencionar el «Acta de compromiso de seguridad nacional» (diciembre de 1973); la Ley de Seguridad Nacional 20.840 (septiembre de 1974) en cuyo artículo $1^{\circ}$ se detallaban las «penas por actividades subversivas en todas sus manifestaciones» dirigidas a todo aquél que «intente o preconice por cualquier medio, alterar el orden institucional o la paz social de la Nación»; el Decreto 1368 del PEN disponiendo el Estado de Sitio por tiempo indeterminado (noviembre de 1974); las leyes de prescindibilidad: 20.549 y 20.713 (octubre de 1973 y agosto de 1974 respectivamente; el Decreto 261 (febrero de 1975, secreto) que autorizaba al Ejército a realizar las operaciones militares necesarias para neutralizar y/o aniquilar el accionar de elementos subversivos en Tucumán.
} 
tos perpetrados por bandas clandestinas paraestatales contra el «enemigo interno», como la Alianza Anticomunista Argentina (AAA) manejada desde el Ministerio de Bienestar Social de la Nación y que en Córdoba desarrolló su máxima actividad durante la intervención de Lacabanne, ${ }^{12}$ sustituida luego por el Comando Libertadores de América (CLA) vinculado al Comando del Tercer Cuerpo de Ejército, que comenzó su accionar en agosto de 1975. ${ }^{13}$ Durante 1974 y 1975, 136 personas fueron desaparecidas y/o asesinadas por razones políticas, mientras que entre el $1^{\circ}$ de enero y el 23 de marzo de 1976 se produjeron 9 ejecuciones sumarias y 44 desapariciones forzadas (Romano, 2017 b).

El golpe de Estado del 24 de marzo de 1976, encabezado por una Junta Militar, y su autodenominado Proceso de Reorganización Nacional (PRN) llevó esas prácticas clandestinas a dimensiones inéditas y exponenciales de manera brutal, sistemática y planificada y «habilitó» más de 350 centros clandestinos de detención y exterminio para su propósito de «aniquilar la subversión», ese enemigo difuso que incluyó a militantes políticos de izquierda -armada y no armada-, delegados y dirigentes gremiales, estudiantiles y sociales, defensores de presos políticos, religiosos progresistas, entre tantos otros opositores. La dictadura «institucional», «fundacional»y «constituyente», según la caracterización de Hugo

\footnotetext{
${ }^{12}$ Sus integrantes «eran civiles y estaban vinculados a distintos espacios de la administración pública local, como el Banco Social, el Ministerio de Bienestar Social, la Secretaría de Seguridad de la Intervención y también algunos sindicatos vinculados al peronismo de derecha, como la Comisión Normalizadora del SMATA. Por entonces, el Departamento de Informaciones de la Policía de la Provincia de Córdoba (D2) se convirtió en el epicentro de la represión y elaboró un 'registro de extremistas' (...) funcionando «como un engranaje más en el sistema generalizado y sistemático de persecución política». Cf. Megacausa «La Perla» (2012, p.16)

${ }^{13}$ Hay que recordar que además de los numerosos atentados y allanamientos contra sindicatos, partidos políticos, medios de comunicación, abogados, etc. ocurridos en Córdoba, el 16 de septiembre de 1974 fueron asesinados en Buenos Aires el ex vicegobernador de Córdoba Hipólito Atilio López junto a su ex Secretario privado y Subsecretario de Hacienda del gobierno de Obregón Cano, Juan José Varas; y Alfredo «Cuqui» Curutchet, abogado de presos políticos y de gremios clasistas de Córdoba. El CLA hizo su aparición con el asesinato de la familia Pujadas el 22 de agosto de 1975. En septiembre de 1975 el general Luciano Benjamín Menéndez fue designado jefe del Comando del III Cuerpo de Ejército, con asiento en Córdoba. En virtud de la directiva 1/75 de octubre del '75, que incluyó a Córdoba, se dispuso que todas las fuerzas de seguridad y de inteligencia quedaran subordinadas al Ejército, como responsable de dirigir las operaciones conjuntas en la lucha de contra la «subversión». Asimismo, desde fines de 1975 funcionó el Centro Clandestino de Detención, Tortura y Exterminio en el Campo de la Ribera, antigua cárcel militar. Megacausa «La Perla» (2012)
} 
Quiroga (1994), terminó de demoler el Estado de derecho. De acuerdo con el autor, a diferencia de lo ocurrido durante el gobierno peronista, la dictadura de 1976 no apeló a una Constitución existente sino que se arrogó el poder constituyente, porque sus actos y normas estuvieron por encima de la Constitución Nacional; y al atribuirse ese poder «supremo» se asignó poderes ilimitados. En nombre de las Fuerzas Armadas, la Junta Militar, invocando un «estado de necesidad», se apropió del poder constituyente y sometió a su voluntad a los demás poderes. ${ }^{14}$ Se trataba en suma de concentrar y centralizar el poder en sus manos, desarticular toda disidencia y protesta social, eliminar las conquistas laborales y disciplinar al conjunto de la sociedad. ${ }^{15}$ En función de ello se revistió de un ropaje «legal» y dictó, de manera discrecional, miles de leyes y decretos. Si bien el PRN ratificó o mantuvo parte de la legislación anterior, como el estado de sitio y la ley de seguridad, ya citadas, para Victoria Crespo (2014) resulta paradójico que «la dictadura instalada en 1976 (...) simultáneamente creó inusitados espacios de violencia y ausencia del Estado de derecho y uno de los ordenamientos más legalistas de la historia moderna argentina» (p.165). ${ }^{16}$ Retomaré esta idea en el análisis del tema que nos ocupa.

\footnotetext{
${ }^{14}$ Quiroga plantea asimismo que «En el vértice de la pirámide jurídica se ubica el Acta y el Estatuto para el Proceso de Reorganización Nacional y toda otra disposición originada en el gobierno de facto. De allí, por consiguiente, toda la voluntad fundacional que emana del poder constituyente» (p. 28-30). El Acta del PRN planteaba como propósito «Restituir los valores esenciales que sirven de fundamento a la conducción integral del Estado, enfatizando el sentido de moralidad, idoneidad y eficiencia [...] erradicar la subversión y promover el desarrollo económico....», BO, 29 de marzo de 1976, citado por Quiroga (p. 59).

${ }^{15}$ Ibíd. Véase también Groisman (1984)

${ }^{16}$ Durante el período 1976-1983 la dictadura sancionó 1.783 leyes nacionales y 18.146 decretos. http://edant.clarin.com/suplementos/especiales/2006/03/24/1-01164121.htm. Mencionamos sólo algunas vinculadas al objeto de este artículo. Buena parte de las leyes dictadas por la junta militar, asistida por la Comisión de Asesoramiento Legislativo (CAL), apenas producido el golpe del 1976, afectaron al ámbito laboral: ley 21.260 (24 de marzo de 1976, autoriza a dar de baja a los empleados públicos «por razones de seguridad»); ley 21.261 (suspende el derecho de huelga «y toda medida que pueda afectar la productividad»); ley 21.263 (suprime el fuero sindical especial); ley 21.274 (29 de marzo de 1976, de «prescindibilidad»; art. $3^{\circ}$ : «Las bajas serán efectivizadas teniendo en cuenta la necesidad de producir un real y concreto proceso depurativo de la Administración pública, sin connotaciones partidistas o sectoriales»). Entre marzo y mayo se intervinieron militarmente a casi todas las organizaciones gremiales de segundo grado y a la vez se prohibió la actividad sindical y la negociación colectiva (21.307).
} 
Entre 1976 y 1982 en Córdoba se sucedieron cuatro gobernadores militares nombrados directamente por la Junta. ${ }^{17}$ En ese lapso el terrorismo de Estado desapareció y asesinó cerca de 1000 personas, una parte de las cuales se desempeñó en la administración pública, sobre lo que volveré más adelante. ${ }^{18}$

En ese contexto y retomando nuestros principales interrogantes sobre el tema, nos preguntamos: ¿Qué tipo de dispositivos emplearon los distintos gobiernos del período para perseguir, sancionar, disciplinar, a los trabajadores y en suma «depurar» la administración pública de Córdoba? ¿En qué medida se sirvieron de leyes y decretos para justificar y legitimar sus acciones represivas? ¿Cómo se articulaba la normativa con la represión ilegal y clandestina? ¿Cuáles fueron las alternativas que encontraron los trabajadores para eludir potenciales sanciones?

\section{Acerca del marco interpretativo}

Para abordar el análisis resumimos a continuación algunas conceptualizaciones que, además de las ya expuestas, orientaron nuestra investigación.

Compartimos con Oszlak (2006) la perspectiva que concibe al Estado como instancia de articulación y dominación de la sociedad y cuando expresa que:

Cada nuevo régimen intenta alterar no sólo las relaciones de poder dentro de la sociedad civil, en línea con su concepción política y la necesidad de fortalecer sus bases sociales de apoyo, sino también la estructura de poder dentro del mismo aparato estatal. Para hacer viable un proyecto político, se requiere actuar sobre -como también mediante- una estructura burocrática preexistente (pp.7-8)

Siguiendo a Max Weber y sus aportes en relación al concepto de burocracia, Di Liscia y Soprano (2017) advierten que «La autoridad bu-

\footnotetext{
${ }_{17}$ Gral. de brigada José Antonio Vaquero (24/03/76-12/04/76, interventor); y los «gobernadores» Gral. de brigada Carlos Alberto Chasseing (12/04/76-02/02/79); Cnel. (R) Miguel Ángel Marini (02/02/79-08/03/79 gob. interino); Gral de brigada Adolfo Sigwald $(\mathrm{R})(08 / 03 / 79-20 / 01 / 82)$.

${ }^{18}$ El mismo 24 de marzo fue secuestrado René Salamanca, secretario general del SMATA hasta su intervención en agosto de 1974, además de otros 10 delgados gremiales y militantes políticos. Desde 1974 tanto Salamanca como Agustín Tosco tenían orden de captura.
} 
rocrática se ejerce mediante leyes u ordenamientos administrativos, mediante el principio de sectores jurisdiccionales estables y oficiales organizados normativamente»(p.13). Las normas establecen principios para la acción y proporcionan instrumentos legítimos para asegurar que las actividades desarrolladas por las agencias burocráticas estén en línea con esos criterios. Para Oszlak (2006) este sistema opera en base a tres mecanismos, uno de los cuales es

el sistema de sanciones, que establece el dominio para el ejercicio de la autoridad y provee los medios para asegurar su aplicación, regulando así las relaciones superior-subordinados. Representa, por lo tanto, el instrumento que aplican aquellos que poseen autoridad para asegurarse que las actividades se conducirán de acuerdo a los objetivos y procedimientos predeterminados (p.10).

Por su parte, Bourdieu (2015) sostiene que la legitimación jurídica es la legitimación simbólica del poder. Los juristas «actúan como bisagra, puesto que regulan las prácticas de delegación y, al mismo tiempo, elaboran teoría constitucional capaz de fundamentar esas prácticas...» (p.415). Para Bourdieu, el cuerpo de agentes y juristas juega un papel determinante en la construcción del campo burocrático donde se inventan las instituciones burocráticas (el despacho, el secretario, la firma, el sello, el decreto de nombramiento, el certificado, el atestado, el registro, etc.) y observa que los funcionarios, como instrumentos de la racionalización del poder, son desde su origen «quienes introducen el rigor, la escritura, el registro, el archivo, operaciones todas identificadas con la burocracia» (p.511).

\section{Breve estado de la cuestión}

Varios autores han señalado que los estudios centrados en las burocracias estatales y en la historia de la administración pública Argentina se incrementaron en los últimos 20 años. ${ }^{19}$ Sin embargo, la mayor parte de la historiografía se ha ocupado y se ocupa de los sujetos y/o de los elencos que formaron parte de las burocracias estatales (funcionarios,

\footnotetext{
19 Di Liscia y Soprano (2017, p. 33). Los autores hacen una revisión de los principales aportes publicados en trabajos colectivos e individuales. Lvovich (2017). Véase también bibliografía adjunta.
} 
profesionales, intelectuales, etc.), sus trayectorias, redes e interacciones sociales, así como de las estructuras organizativas y las políticas públicas de algunas instituciones del Estado. Y en general, se coincide en observar que los niveles provincial y local de la administración pública han quedado notoriamente sub-estudiados frente al predominante nivel nacional. ${ }^{20}$ En este sentido, además, son escasos los estudios que abordan específicamente las modalidades, las prácticas y la normativa empleadas al interior de la administración pública para reprimir, sancionar, perseguir, controlar y disciplinar a sus agentes durante regímenes autoritarios o dictatoriales, en particular de la segunda mitad del siglo XX y más específicamente durante la última dictadura (1976-1983). ${ }^{21}$ Para el caso de Córdoba, la actividad gremial y las luchas de los empleados públicos en su conjunto -sea en el ámbito provincial o municipal- han sido escasamente estudiadas, existiendo algunos trabajos focalizados en sectores de trabajadores, empresas, poderes u organismos estatales descentralizados $^{22} \mathrm{o}$ en el marco de la historia del movimiento obrero, más centrada en la de trabajadores del sector metal mecánico y de los sindicatos líderes de Córdoba, como Luz y Fuerza. ${ }^{23}$

\section{La trama burocrática, los dispositivos}

Si bien consideramos dos sub períodos del lapso 1974-1978, podemos adelantar que aunque se advierten rasgos de continuidad y solapamiento de la legislación y los mecanismos represivos de las intervenciones federales y los gobiernos de facto de la provincia, destaca de exa-

\footnotetext{
${ }^{20}$ Entre los más recientes véanse las publicaciones colectivas de Bohoslavsky y Soprano (2010), Di Liscia y Soprano (2017), Osuna y Vicente (2017), Palermo y Silva (2016), Bertranou, Palacio y Serrano (2004).

${ }^{21}$ Posinio (2016). Para el caso de Córdoba: Romano (2007), San Nicolás (2016), Arriaga (2017).

22 Por ejemplo los artículos de Bohoslavsky (2016) sobre la huelga de los médicos no rentados y de Arriaga (2016) sobre los trabajadores de EPEC. El trabajo realizado por Peña (2000), si bien se trata de una historia institucional del Sindicato de Empleados Públicos, patrocinada por el mismo y por el gobierno provincial, contiene elementos de interés histórico, aunque presenta sesgos y omisiones, como las referidas al período 1974-1983, entre ellas el Estatuto del Empleado Público, o la nómina de miembros de comisiones directivas del sindicato. Cf. Romano (2018, pp.9-11).

${ }^{23}$ Principalmente véanse Brennan (1996); Brennan y Gordillo (2008) o más recientes, por ejemplo Ortíz (2019).
} 
cerbación de los dispositivos de control y punitivos durante este último, particularmente la superproducción de leyes, decretos y resoluciones, de manera análoga a lo señalado sobre el PRN para todo el territorio nacional. En esa trama destaca el recurso a procedimientos burocráticosadministrativos y argumentaciones legalistas sustentadas en la normativa (previa y la producida al efecto) legitimadas por la asesoría letrada de la administración que parecen prevenirse de futuros reclamos de los agentes afectados. Una trama donde la norma, la escritura, la firma, el sello de la autoridad y el archivo se constituyen en prácticas rutinarias. En este contexto y como ya lo anticipamos, pondremos el foco principalmente en tres normativas $(5719 ; 5911$ y 5913$)$ que, entendemos, fueron empleadas para perseguir y cesantear a activistas gremiales, opositores contestatarios y militantes políticos y, al mismo tiempo, amedrentar y disciplinar al conjunto de los trabajadores; evaluando sus efectos cualitativos y cuantitativos, incluyendo en ello a los renunciantes. Seguidamente, y sobre la base de la documentación disponible, sostendremos asimismo que ese conjunto de normas y procedimientos burocráticos-administrativos se articularon e imbricaron estrechamente con la creciente persecución ideológica, la represión ilegal y el terrorismo de Estado que caracterizaron el período.

\section{Las fuentes. Aspectos metodológicos}

Para la actual investigación consultamos centralmente decretos de los años 1977 y 1978 custodiados en el Archivo de Gobierno de la Provincia de Córdoba(AGPC), protocolizados en la Serie Única de Decretos (SUD), que reúnen 10.038 y 10.216 decretos respectivamente. Estos remiten a 145 tomos para 1977 y a 154 para 1978, donde relevamos sistemáticamente cesantías, bajas, ceses de funciones -según la terminología empleada en cada caso acorde con la aplicación de una u otra norma- las recisiones de contratos, así como las producidas al dejar sin efecto designaciones previas. Excluimos en todos los casos a funcionarios jerárquicos de gobierno y al personal policial. Si bien, como se verá, el relevamiento y el análisis de los datos se hizo con fines interpretativos de manera desagregada según las categorías señaladas, los agregamos bajo las de cesantías (aplicación del Estatuto y otros particulares como el del ex Poder Legislativo), bajas (incluye aplicación de leyes 5911, 5913, cese de funciones y bajas docentes), recisión de contratos y designaciones dejadas sin efecto. 
A su vez registramos las renuncias de empleados, excluyendo también a funcionarios de gobierno y a quienes se acogían a la jubilación. Adicionalmente, relevamos los recursos de reconsideración presentados por damnificados de las leyes de la dictadura (5911 y 5913). Asimismo recogimos algunos testimonios de ex empleados de la administración pública, aunque aquí sólo haremos referencia a una parte de ellos.

Los documentos secretos ya mencionados que empleamos en esta ocasión refieren, entre otras cuestiones, a la aplicación de los tres instrumentos legales y a la organización del Sistema de Comunicación Social para la lucha contra la Subversión en apoyo de la Acción del Gobierno. También recurrimos a documentación reservada de la SIDE que obra en la Justicia Federal de la Provincia. ${ }^{24}$ Toda la información relevada se cruzó con los datos sobre desaparecidos y asesinados de Córdoba, lo que permitió establecer y/o ampliar las trayectorias laborales de 63 personas (ver nómina adjunta). ${ }^{25}$

\section{La trama normativa, sus aplicaciones ${ }^{26}$}

Uno de los principales instrumentos legales para disponer cesantías, bajas de personal y dejar sin efecto designaciones fue el Estatuto del Personal de la Administración Pública de la Provincia (ley 5719, BO 19/ $3 / 74$, en adelante Estatuto, decreto reglamentario $\mathrm{N}^{\circ} 5445$, noviembre de 1975), que ofrecía un detalle de quienes estaban amparados por la norma, así como de quienes no lo estaban; los derechos, los «deberes y prohibiciones» de los primeros, el régimen disciplinario, que incluía la gradación de sanciones y las causales de las medidas disciplinarias así como las autoridades de aplicación en cada caso. Preveía asimismo con minuciosidad los motivos para el otorgamiento de licencias, como también las condiciones para la aceptación de renuncias. Además, el articulado de la ley incluía, entre otros aspectos, el escalafón del personal y su agrupamiento en diferentes categorías, remuneraciones, etc.

\footnotetext{
${ }^{24}$ Para su consulta y empleo cuento con la expresa autorización del Juzgado Federal No 3 de Córdoba en la causa «Pérez Esquivel Adolfo y Martínez María Elba s/Presentación» (Expte. FCB 35009481). Carpetas SIDE (Casos 35-42 y 40-41)

${ }^{25} \mathrm{El}$ cruce de datos se hizo con la nómina documentada de personas desaparecidas y asesinadas de Córdoba, publicada en Romano (2017 b).

${ }^{26} \mathrm{El}$ análisis de la normativa citada y los datos construidos hasta 1976 inclusive fueron recuperados de nuestro trabajo anterior (Romano, 2018).
} 
Justamente, a partir de la aplicación del Estatuto una de las primeras disposiciones del interventor Brunello -con la firma de varios ministros y secretarios de gobierno- dejó sin efecto todas las designaciones de personal efectuadas por decreto entre el $1^{\circ}$ de enero y el 14 de marzo de 1974, en vistas a la confirmación, revisión, cambio de categoría o anulación de las mismas. El decreto aclaraba que éste no comprendía a quienes gozaban de estabilidad en el cargo. ${ }^{27}$

Tanto las designaciones masivas al finalizar un mandato como las bajas de las mismas al iniciarse el siguiente fueron prácticas corrientes durante todo el período. $\mathrm{Al}$ asumir Lacabanne como interventor, dictó el decreto 5004 (14/10/74) en el que daba de baja a 115 agentes nombrados el 5/9/74 en distintas reparticiones, aclarando no obstante que cada ministerio y secretaría podría proponer confirmaciones, cambios de categoría o destino. A su vez, Bercovich Rodríguez dejó sin efecto numerosos nombramientos realizados durante la intervención de Lacabanne. ${ }^{28}$ Por ejemplo, mediante el decreto 4102 (14/10/75) las designaciones protocolizadas en 35 decretos correspondientes a 1975. Del mismo modo se sucedieron designaciones masivas a fines de 1975, durante la intervención de Bercovich Rodríguez y de Carlos Risso (interventor interino).

Retomando las cesantías, éstas se sustentaron en general en lo establecido por el Estatuto con argumentos tales como numerosas faltas injustificadas, abandono del cargo, no reintegrarse después de una licencia. En la mayoría de los casos, las inasistencias o abandono del cargo databan de varios meses atrás. Entre las bajas por «fallecimiento» se registran las de personas desaparecidas y asesinadas por razones políticas, por ejemplo en junio de 1974 la de Guillermo Tomás Burns, y en abril de 1975 la de Juan José Varas, en su cargo docente del nivel medio. $^{29}$

\footnotetext{
${ }^{27}$ AHPC, Decreto No 2198, 31/5/74. En los casos no incluidos en el Estatuto, como el del personal médico hospitalario o en programas especiales, los decretos aludían a expedientes, etc. por ej. del Ministerio de Bienestar Social. Cf. Ibíd., D. No 4430, 05/09/74, «baja por abandono del cargo».

${ }^{28}$ No ha sido posible contabilizar todas las designaciones dejadas sin efecto, tanto por el volumen de la masa documental consultada, como porque en algunos casos se excluía luego a un cierto número de personas o bien eran reincorporadas. Sólo los decretos de designaciones (individuales y colectivas) realizadas por Lacabanne entre el 15 y el 19 de septiembre de 1975 ocuparon tres folios completos del tomo 13 de la SUD.

${ }^{29}$ Burns, hallado muerto luego de su secuestro el 21/12/73, se desempeñaba como preceptor en una escuela técnica; sobre Varas ver cita $\mathrm{N}^{\circ} 12$.
} 
En cuanto a las renuncias, si bien aún no podemos considerar si fueron voluntarias o inducidas, ${ }^{30}$ es de hacer notar que las mismas resultaron masivas sobre todo en períodos inmediato anteriores y posteriores al Navarrazo y especialmente a la llegada de Lacabanne (cf. Cuadro 1); pero también al iniciarse y concluir el período de Bercovich Rodríguez. ${ }^{31}$ Teniendo en cuenta lo expresado por algunos entrevistados que renunciaron en este período, lo hicieron «para sobrevivir». Se observa asimismo que los decretos de aceptación de las renuncias «por razones particulares» son en general, bastante posteriores a su presentación. Abundan los decretos que incluyen a un gran número de trabajadores $\mathrm{y}$, aunque los había de distintas reparticiones, buena parte de las renuncias eran de las áreas de salud y educación. En numerosos casos, los renunciantes eran militantes políticos y/o gremiales, varios de ellos luego desaparecidos, por lo que resulta razonable interpretar en esa decisión la intención de preservarse de la represión, al igual que los pedidos de licencias prolongadas previas a sus renuncias, el no reintegrarse tras estas o abandonar sus cargos. ${ }^{32}$

El siguiente cuadro, recuperado de nuestro trabajo anterior, muestra comparativamente los datos construidos en base a decretos para el período 1974/1976.

\footnotetext{
${ }^{30}$ Las entrevistas realizadas a ex agentes todavía resultan insuficientes para sustentar una interpretación de esa naturaleza.

${ }^{31}$ Sólo entre enero y marzo de 1976, previo al golpe de estado, se produjeron más de 100 renuncias.

32 Francisco F. Yofre, en una comunicación personal por correo electrónico el 12/12/18, expresaba que «los militantes apelaban a las licencias prolongadas para tratar de protegerse de la represión, por ejemplo en mi caso. yo tomé mi licencia por casamiento en mayo de 1974 y le sumé seis meses de licencia sin goce de sueldo. Esto motivó que varias compañeras de mediana edad del Banco Social expresaran: 'no entiendo como este chico recién casado se tome licencia sin goce de sueldo, cuando está en una etapa de su vida en la que va necesitar dinero'. Al reincorporarme a fines de diciembre de 1974, trabaje unos días, y pedí la licencia ordinaria en febrero de 1975. A fines de ese mes cuando la D2 me busca no me presento a trabajar, y el directorio me deja cesante por abandono de tareas, Recién en julio de 1976, el interventor general de brigada Chasseing me da de baja por un decreto suyo.»
} 
Cuadro 1. Registro general de cesantias, bajas de personal y renuncias (1974-1976)

\begin{tabular}{|c|c|c|c|c|c|c|}
\hline Período & Interventor & Cesantías & Bajas & $\begin{array}{c}\text { Recisión de } \\
\text { contrato }\end{array}$ & $\begin{array}{c}\text { Dejan sin efecto } \\
\text { designaciones }\end{array}$ & Renuncias \\
\hline $\begin{array}{l}28 / 02 / 74- \\
06 / 09 / 74\end{array}$ & $\begin{array}{l}\text { Agodino } \\
\text { Brunello }\end{array}$ & 19 & 23 & 1 & $\begin{array}{l}\text { D. No } 2198(31 / 05 / 74) \text { las } \\
\text { efectuadas entre el } 2 / 1 \text { y } 14 / \\
3 / 74 \text {, sin detallar. }\end{array}$ & 544 \\
\hline $\begin{array}{l}07 / 09 / 74- \\
19 / 09 / 75\end{array}$ & Lacabanne & 31 & 142 & 8 & 40 D. N $2520(27 / 06 / 75)$ & 1.111 \\
\hline $19-20 / 9 / 75$ & Gral. Menéndez & - & - & - & - & - \\
\hline $\begin{array}{l}20 / 09 / 75- \\
23 / 03 / 76\end{array}$ & $\begin{array}{l}\text { Bercovich } \\
\text { Rodríguez }\end{array}$ & 7 & 11 & 3 & $\begin{array}{l}53+14 \text { del decreto } 4102 \\
(14 / 10 / 75) \text { que dejaba sin } \\
\text { efecto } 35 \text { decretos de } \\
\text { designaciones firmados por } \\
\text { Lacabanne entre el } 12 \text { y el } \\
\text { 19/9/1975, } 21 \text { de los cuales } \\
\text { eran designaciones colectivas } \\
\text { (no contabilizadas) }\end{array}$ & 450 \\
\hline Totales & & 57 & 176 & 12 & 107 (incompleto) & 2.105 \\
\hline
\end{tabular}

Fuente: Romano (2018) 
Después del golpe de Estado del '76, las primeras disposiciones adoptadas por el gobierno de facto en Córdoba para dar de baja al personal oscilaron entre la difusa referencia a «instrucciones impartidas por el Gobierno nacional» y al Estatuto, aunque muy pronto dictó las normas que les fueron funcionales para realizar despidos masivos por «razones de seguridad» (ley 5911, BO 6/4/76) ${ }^{33}$ y por la pretendida «depuración» $\mathrm{y}$ «racionalización» o ley de prescindibilidad (ley 5913, BO, 12/ 4/76) de amplio alcance, ${ }^{34}$ sin dejar por ello de recurrir al Estatuto o al específico de otros poderes cuando resultó conveniente y/o pertinente. Muy pronto también se dejaron sin efecto más de 140 designaciones realizadas entre fines de 1975 y comienzos de 1976 en diversas reparticiones, pero sobre todo en hospitales y otras dependencias sanitarias, con el argumento de que los nombrados aún no habían tomado posesión del cargo. ${ }^{35}$

Entre la batería de normas dictadas en los primeros meses de 1976 para efectivizar los despidos y la persecución ideológica y política, las leyes 5911 y 5913 fueron las más empleadas. Ambas estaban articuladas entre sí para disponer si correspondía o no indemnización al trabajador despedido (Art. $5^{\circ}$, ley 5913). Como complemento de la misma, el decreto 425 (4/5/76) argumentando «la necesidad de implementar de forma inmediata la racionalización de la Administración Pública dispuesta

\footnotetext{
33 «Art. $1^{\circ}$ AUTORIZASE al Titular y Ministros del Poder Ejecutivo Provincial, hasta el 31 de diciembre de 1976, a dar de baja, por razones de seguridad, al personal permanente, de gabinete, interino, contratado, transitorio, suplente, que se desempeñe en la Administración Pública Provincial, Legislatura Provincial, Tribunal de Cuentas de la Provincia, Organismos descentralizados, Autárquicos, Empresas y Bancos del Estado, Empresas paraestatales y toda otra dependencia del Poder Ejecutivo Provincial, que se desempeñen bajo cualquier título, vinculo jurídico, denominación y amparados por estatutos o régimen especiales vigentes, que de cualquier forma se encuentre vinculado a actividades de carácter subversivo o disociadoras, o que en forma abierta, encubierta o solapada preconicen o fomenten dichas actividades».

${ }^{34}$ «Artículo lo. - Autorizase al titular del Poder Ejecutivo Provincial, hasta el 31 de diciembre de 1980 a dar de baja por razones de servicio, al personal permanente, de gabinete, interino, contratado, transitorio, suplente o eventual, que se desempeñe bajo cualquier título, vínculo jurídico, denominación, amparado por cualquier estatuto, convenio o régimen especial vigente en la Administración Pública, Organismos Descentralizados, Autárquicos, Empresas y Bancos del Estado, Empresas Paraestatales, Servicios de Cuentas Especiales, Obras Sociales, Servicios Educativos y toda otra dependencia del Poder Ejecutivo Provincial; Legislatura Provincial; Poder Judicial de la Provincia; Tribunal de Cuentas de la Provincia y Municipalidades de Capital e Interior de la Provincia.
}

${ }^{35}$ Decreto 267 (09/04/1976). 
por el Superior Gobierno de la Nación...» y razones de «eficiencia» que impedían atender a los problemas de los habitantes, realización de obras públicas y otros, debido al «sobredimensionamiento del personal», junto con el decreto 426 (04/05/76), daba de baja «de pleno derecho» al personal permanente que hubiese sido designado y/o dado de alta entre el 5 de noviembre de 1975 y el 24 de marzo de 1976, así como el comprendido en el decreto $\mathrm{N}^{\circ} 399$ del 30/04/76.

El decreto 425 , complementado o no con la ley 5913 o el Estatuto, fue empleado a lo largo del año para justificar bajas por «razones de servicio», «cese de funciones»-por ejemplo para contratados o personal de casinos-, dejar sin efecto designaciones, como también para denegar recursos de reconsideración en el caso de pedidos de reincorporación. En ese marco y en el de la exacerbación de las medidas represivas se ampliaron los alcances de la ley 5913 y se dictaron otras vinculadas, como las que suspendían derechos y habilitaban bajas discrecionales, arbitrarias y por razones político-ideológicas en el ámbito de la educación pública y privada, como se verá más adelante.

Los argumentos legales empleados por los funcionarios de la dictadura resultaron muchas veces contradictorios, excesivos y arbitrarios como las mismas leyes. Las referencias a los «derechos constitucionales» y otra terminología empleada, como «conforme a derecho» o «conducta antijurídica» resultan sorprendentes, pero dan cuenta del propósito de auto legitimación y el de prevenirse ante posibles reclamos.

Como en el período anterior, en general las cesantías se fundamentaban con una serie de argumentos legales, sobre todo cuando se aplicaba el Estatuto. Igualmente, aunque mucho más abundantes, las causas se originaban en faltas injustificadas -10 o más-, el abandono del cargo o no reintegrarse a sus funciones después de una licencia, hechos en su mayoría ocurridos con bastante antelación al decreto correspondiente. Además se dejaba constancia del sumario labrado, las notificaciones enviadas y la falta de respuesta de los empleados, tratándose en varios casos de personas desaparecidas. Sin embargo, en 1977 y sobre todo en 1978, buena parte de las cesantías se originaron en el rechazo de renuncias previas, en general porque no cumplieron los requisitos establecidos en la normativa (30 días de funciones tras la solicitud, si aún no se hubiese resuelto la aceptación de la renuncia). Pero, algunos casos se presentan como medidas arbitrarias o, tal vez, como consecuencia del laberinto burocrático. ${ }^{36}$ Tan arbitraria y con clara intención de ocultar

${ }^{36}$ Por caso, Abel Bohoslavsky, ex médico del hospital Rawson, en comunicación personal 
una desaparición forzada resulta la cesantía de Vialidad Provincial de Pablo Eduardo Ochoa, dispuesta el 10 de noviembre del ' 78 por tener más de cuatro faltas injustificadas desde31/5/76, coincidentes con la fecha de su secuestro el 26/5/76. ${ }^{37}$ También llama la atención que muchos de los cesanteados fuesen personas mayores, es decir que en poco tiempo se hubiesen podido jubilar.

Mención aparte merecen las cesantías sustentadas en la ley 5911, destinada a la persecución política e ideológica del personal. En algunos casos la disposición afectaba a un conjunto de personas con la sola mención de la ley. La misma se aplicó sobre todo en abril de 1976 y hasta fines de ese año, como se observa en el decreto del 31 de diciembre que daba de baja a personal de Salud Pública y de Educación y Cultura e incluía a Julia Brocca quien había sido secuestrada y desaparecida el 28/ 03/76. En otros casos, se les daba de baja por «fallecimiento», eufemismo empleado también en los años 74 y 75 para referirse a personas asesinadas por razones políticas. Entre ellas, a Marcela Josefina Guzmán, asesinada el 19/12/75; a Mirta Noemí Abdón o a Héctor Hugo Ghisolfi, asesinados en 1976, pocos meses antes del decreto (Romano 2917a y 2018).

Las renuncias por razones particulares presentadas por los trabajadores en este período, muestran el mismo comportamiento descrito para el anterior. Asimismo, en numerosos casos el decreto de aceptación es muy posterior a la fecha de la presentación del renunciante $y$, aunque las había de distintas reparticiones, la mayoría correspondía a personal de educación y salud, tanto de capital como del interior. Cabe señalar en ese marco que el grueso de las renuncias de personas, luego desaparecidas y/o asesinadas, se produjo entre 1974 y 1975.

El Cuadro 2 registra los despidos producidos en los años 1976, 1977 y 1978, bajo las categorías agrupadas según lo expuesto más arriba, y las renuncias relevadas en este período.

por correo electrónico el 9/10/18 y en respuesta al envío de la copia digital de su «baja» en 1977 , relataba que «1) Yo pedí licencia sin goce de sueldo en noviembre 1975, la que me fue concedida sin problema y rápidamente, por un período de seis meses; 2) En mayo 1976 envié mi renuncia por escrito que alguien presentó en el hospital y fue aceptada. Me dieron certificación de servicios acreditando mi trabajo [por el] período noviembre 73-mayo 76». No obstante, el 06/05/77 un decreto le daba de «baja por razones de servicio» por aplicación de la ley 5913, a partir de esa última fecha.

${ }^{37}$ La cesantía se dispuso a partir del 31/05/76. Ochoa continúa desaparecido. Cf. Romano (2017 b) 
Cuadro 2. Registro general de cesantías, bajas de personal y renuncias (1976-1978)

\begin{tabular}{|l|l|c|c|c|c|c|}
\hline Período & $\begin{array}{l}\text { Interventor /gobern. } \\
\text { de facto }\end{array}$ & Cesantías & Bajas & $\begin{array}{c}\text { Recisión de } \\
\text { contrato }\end{array}$ & $\begin{array}{c}\text { Deja sin efecto } \\
\text { designaciones. }\end{array}$ & Renuncias \\
\hline $\begin{array}{l}24 / 3 / 1976- \\
12 / 4 / 76\end{array}$ & Gral. Vaquero & $152^{*}$ & $995^{*}$ & 110 & $\begin{array}{l}143+\text { decretos sin } \\
\text { especificar número }\end{array}$ & 1.262 \\
\hline $\begin{array}{l}12 / 04 / 76- \\
31 / 12 / 76\end{array}$ & Gral. Chasseing & & & & & \\
\hline $\begin{array}{l}1 / 01 / 77- \\
31 / 12 / 77\end{array}$ & Gral. Chasseing & 175 & 867 & 7 & 31 & 2.736 \\
\hline $\begin{array}{l}1 / 01 / 78- \\
31 / 12 / 78\end{array}$ & Gral. Chasseing & 247 & 375 & 2 & 57 & 2.560 \\
\hline Totales & & $\mathbf{5 7 4}$ & $\mathbf{1 . 8 6 2}$ & 119 & $\mathbf{2 3 1}$ (incompleto) & $\mathbf{6 . 5 5 8}$ \\
\hline
\end{tabular}

Fuentes: elaboración propia 1976 Romano (2018); 1977 y 1978: AGPC, Serie Única de Decretos T.15 y 16 y Decretos, Tomos vs. ${ }^{*}$ Cifras corregidas 
Si consideramos desde el punto de vista cuantitativo los despidos decretados -en cada una de sus variantes- durante los años 1977 y 1978 mediante la aplicación de la legislación ya citada se observan algunos cambios con respecto a lo ocurrido en 1976. Entre ellos se advierte que mientras se incrementaron las cesantías con base en el Estatuto y sus reformas, las bajas producidas con el recurso de las leyes de seguridad (5911) y de prescindibilidad (5913) tendieron a disminuir, en particular hacia 1978. Tomando sólo esta última vemos que se pasó de 742 despidos en 1976, a 748 en 1977 y a 287 en 1978, es decir un total de 1.777.38 También se observa una disminución significativa en la rescisión de contratos y en las designaciones dejadas sin efecto. En cuanto a la ley 5911, no registramos su aplicación en los dos últimos años. Por otra parte, en el rubro «bajas» se advierte un incremento de las de personal docente, particularmente por cierre de cursos y cambios de planes de estudio.

Seguramente la reforma del Estatuto del Empleado Público de 1977 y las nuevas disposiciones que ampliaron la arbitrariedad y la discrecionalidad de los dispositivos legales para la exclusión, así como la restricción de derechos de los trabajadores hizo innecesario el recurso a las leyes citadas. ${ }^{39}$ La reforma del Estatuto no modificó el capítulo sobre el régimen disciplinario, ni el de deberes y prohibiciones, como tampoco las causales de las sanciones, las penalidades correspondientes y las autoridades de aplicación. Sí en cambio eliminó otros capítulos y agregó en las Disposiciones generales y transitorias el artículo que aseguraba el recurso a la excepción: «La estabilidad del agente legislada por el presente Estatuto quedará supeditada a las leyes de prescindibilidad, mientras se mantengan en vigencia las mismas». ${ }^{40}$ Además, agregó como inhabilitación para el ingreso, reingreso o permanencia en un cargo a quien «de cualquier forma se encuentre vinculado a actividades de carácter subversivo o disociadoras o que en cualquier forma preconice o fomente dichas actividades». ${ }^{41}$ Con ello, la reforma se articulaba con la ley 5913 y subsumía la 5911.

${ }^{38}$ Cifra resultante de la suma de los datos relevados en decretos del 13/10/78 al 31/12/78 al proporcionado a la SIDE por el Jefe de Personal de la gobernación. Cf. Romano (2018). ${ }^{39}$ Estatuto del Empleado Público ley 6108 (BO, 22 de noviembre de 1977).

${ }^{40}$ Ibíd., Cap. IX, art. 100. Entre los principales cambios destaca la eliminación de los capítulos IX al XVIII correspondientes a la Junta Asesora (que incluía a dos representantes del sindicato), Escalafón del personal, su clasificación, forma de ingreso, promociones, concursos y agrupamientos.

${ }^{41}$ Ley 6108, BO 11 de noviembre de 1977. 
Por su parte, la ley 6023 (BO 05/04/77) facultaba al PE provincial a suspender total o parcialmente los Estatutos de la docencia primaria, media y superior; y a excluir de las listas de órdenes de méritos respectivas a las personas comprendidas en el artículo anterior, como así también a no darles destino y no designarlas, aún en caso de que hubieren sido incluidas, propuestas y puestas a cargo. Poco después, la ley 6032 (BO, 20/05/77) lo facultaba a «inhabilitar para desempeñarse en los Establecimientos de Enseñanza Privada de la Provincia comprendido en la Ley 5326, al personal docente y no docente que haya sido dado de baja por aplicación de la Ley Nacional 21.260, de la Ley Provincial 5911 o de leyes similares dictadas por otros Estados Provinciales, o que de cualquier forma se encuentre vinculado a actividades subversivas o disociadoras, como asimismo a aquellos que en forma abierta, encubierta o solapada preconicen o fomenten dichas actividades». En suma, se dejaba fuera de la administración pública a un indeterminado número de docentes y no docentes de todos los niveles sin necesidad de aplicar la legislación específica para cesantearlos.

Como se observa en el Cuadro 2, las renuncias presentadas muestran un aumento exponencial en 1977 y 1978, duplicando o más las de 1976. Quedan pendientes de interpretación las motivaciones de las mismas, que suponemos vinculadas al clima represivo dentro y fuera de la administración, a la sedimentación de una «cultura del miedo». ${ }^{42}$ No obstante, el sondeo de algunos casos todavía aislados indicaría que en el área de salud se justificaban por los bajos salarios y, en el de los docentes, que renunciaban a horas cátedra o a un cargo, por conservar o por haberse incorporado a otros.

El Gráfico I muestra comparativamente el comportamiento de la totalidad de las exclusiones de la administración pública, que agregamos bajo el rubro «despidos varios», y de las renuncias por razones particulares. Hemos unificado el período 1974-1975 de la intervención federal para una mejor lectura.

\footnotetext{
42 Tomamos este concepto de Corradi (1996, p. 89). El autor señala que, al ser el terror una forma de poder en la cual la conformidad no garantiza la seguridad, «su efecto es la generación de una atmósfera de ansiedad 'una cultura del miedo'»; también tiene un efecto residual que no se limita a la presencia real de la coerción arbitraria y rigurosa que perdura en el tiempo y el medio circundante. Véase también Romano (2007).
} 
Gráfico I: Despidos y renuncias 1974-1978 (cifras agregadas)

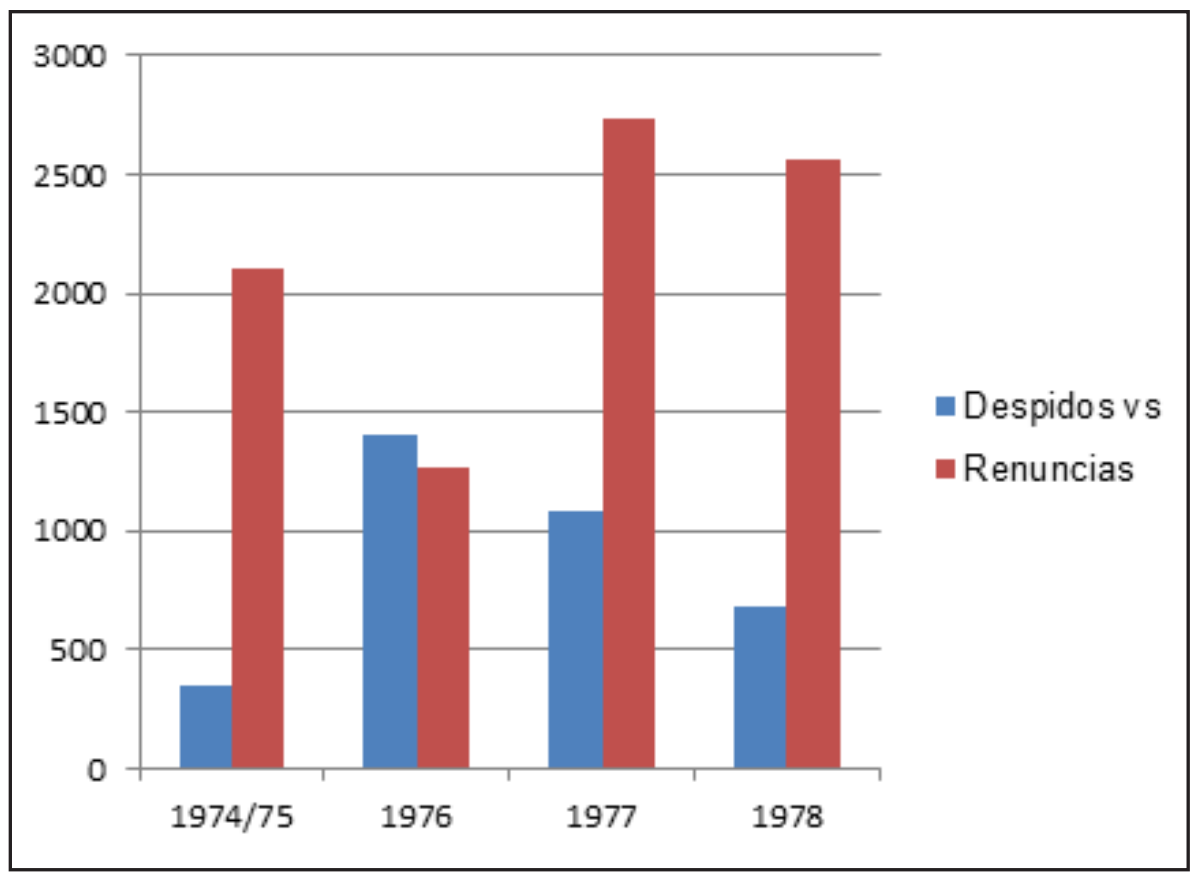

Fuente: elaboración propia en base a Cuadros 1 y 2

\section{Documentos Secretos y Reservados}

En el trabajo anterior a éste planteamos en base a diferentes pruebas que existió una articulación y colaboración de las autoridades de la intervención federal y de facto con los Servicios de Inteligencia del Estado (SIDE) y las fuerzas de seguridad, sosteniendo que la represión legal e ilegal y clandestina no sólo coexistieron sino que también se complementaron. El análisis de algunos documentos secretos producidos por el gobierno de facto entre 1976 y 1978 y de otros generados por la SIDE no sólo confirma esas conclusiones sino que muestran claramente la intencionalidad y la finalidad represora de las autoridades de la administración pública. Como se verá a continuación, esas disposiciones y el «secretismo» cooperaban con las acciones clandestinas del terror estatal, ocultadas bajo un discurso de orden y razones de «eficiencia»y «de servicio», para la «racionalización» y la «depuración» de la administración 
pública «sin connotaciones partidistas ni sectoriales», como rezaba la ley 5913, para dar de baja a miles de empleados.

En primer término, hay que mencionar que en julio de 1976 el gobernador de facto, general Chasseing, dispuso reformar la ley 5350/ 72 (sobre procedimientos administrativos) con el sólo agregado de una cláusula que estableciera en forma expresa las calificaciones de «Reservados» O»Secretos» a los actos del PE en la tramitación de asuntos sobre seguridad y orden públicos, quedando demorada su publicación en el primer caso y excluida en el segundo (ley 5938, BO 13/07/76).

En ese marco, en septiembre del ' 76 , dictó una resolución secreta sobre «normas y procedimientos a seguir en la aplicación de las leyes 5911 y 5913» que al final también incluía artículos del Estatuto (5719). Como se verá, esos procedimientos administrativos no dejaban de ser altamente burocráticos, como todas las actuaciones del período.

Sintéticamente, sobre la ley 591 lproponía que en base a antecedentes solicitados a la Comunidad Informativa, ${ }^{43}$ más elementos de juicio sobre el agente obrantes en su poder, el ministerio correspondiente elaboraría un proyecto de decreto proponiendo la separación del agente, firmado por el titular del ministerio en el que éste revistaba, más la firma del secretario de Estado. Todo este trámite tendría carácter «secreto». Luego el expediente debía ser enviado al ministro de gobierno para su evaluación final y si estuviese de acuerdo lo remitiría a la Secretaría General de Coordinación y Programación para la firma del decreto por el gobernador (adjuntaba modelo). «Firmado el decreto por el titular del PE y como trámite previo a su protocolización se remitirá todo lo actuado al señor Ministro de Gobierno para que el mismo ordene la inmediata detención del agente». ${ }^{44}$ Todo un dispositivo puesto en marcha cuyo fin último era «capturar» a los disidentes.

Con posterioridad al momento en que se tenga conocimiento de la efectiva privación de la libertad del causante y efectuado el desglose precedentemente indicado, se enviará el expediente a la Secretaría General de Coordinación y Programación de la Gobernación para

\footnotetext{
${ }^{43}$ Refiere a la «Comunidad Informativa de Inteligencia», que reunía a los diversos organismos de inteligencia de las Fuerzas Armadas y de Seguridad, a la SIDE y a la Secretaría de Estado de Seguridad del Ministerio de Gobierno de la provincia de Córdoba que, bajo las órdenes del Comando de III Cuerpo de Ejército, intercambiaban información y coordinaban acciones en reuniones secretas y reservadas. Megacausa (2012).

${ }^{44}$ AGPC, Resolución Secreta N³47, 14/09/76.
} 
que realice los trámites faltantes, incluyendo el de la publicación en el Boletín Oficial del decreto respectivo. ${ }^{45}$

Respecto a la ley 5913, en particular sobre si correspondía o no aplicar el artículo $5^{\circ}$ inc. f), es decir no abonar la indemnización al agente despedido, el procedimiento era el mismo e igualmente secreto y se le aplicaría el artículo en el caso de «no contar con elementos de juicio concretos que permitan concluir que se está en presencia de elementos subversivos o vinculados a la subversión, pero que en base a antecedentes obrantes $(. .$.$) pueda fundadamente sospecharse que se está en pre-$ sencia de un elemento potencial o real de perturbación.» Sobre el resto de las «bajas», indicaba que en todos los casos en que no existieran antecedentes, «aun cuando pueda sospecharse que se estaría en presencia de elementos disociadores» se concretaría su separación de la administración pública y con pago de indemnización. Esto, siempre y cuando el agente no estuviera comprendido en otros incisos del artículo $5^{\circ}$, por ejemplo que hubiese ingresado sin cumplir con los requisitos vigentes sobre información previa favorable de la SIDE, la Policía Federal o Provincial.

Dos ejemplos de informes de la $\operatorname{SIDE}^{46}$ sobre el perfil ideológico político atribuido a empleados desaparecidos dan cuenta de la naturaleza subjetivae imprecisa de los mismos y, salvo «nombres y apellido», «N ${ }^{\circ}$ de documento» $\mathrm{y}$ «antecedentes», en general carecen de fecha y otras referencias que permitan vincularlas con decretos del gobierno. Es el caso de Elba Rosa Navarro, secuestrada y desaparecida desde el 16/8/ 76. Los antecedentes registrados en la ficha indicaban lo siguiente: «Pertenece a Protección del Menor. Ideológicamente cercana a la ultraizquierda. Vinculada a CTERA (...). Pertenece a un grupo docente muy peligroso, alguno de los cuales vinculados al copamiento de Villa María (...). Por las funciones que desempeña puede ocasionar graves perjuicios». ${ }^{47}$

${ }^{45}$ El desglose del expediente indicado en el texto, refiere a lo siguiente: en el Ministerio de Gobierno se debía separar el acta o proyecto de decreto firmada por la autoridad responsable y la totalidad de los antecedentes desfavorables, dejándose constancia de ello en un texto (adjuntaba modelo de redacción) en tanto el original sería remitido a la Secretaría de Estado de Seguridad junto con una copia del decreto. El resto del expediente debía archivarse en la Dirección General de Personal.

${ }^{46}$ Carpeta SIDE, Casos 40-41_0197, Carátula «Lista de personas dadas de baja de la Adm. Públ. Después del 24 de marzo 76 y además algunos antecedentes». Sobre la carátula se lee en manuscrito «Fichar». Véase trayectoria en Romano (2017 a)

${ }^{47}$ Carpeta SIDE, Casos 40-41_0137. 
En cuanto a Carlos Alfredo Escobar, secuestrado y desaparecido desde el 29/3/76, dado de baja el 31/12/76por la ley 5913 sin indemnización, la ficha contiene más información, como el encabezado «Ministerio de Educación y Cultura», «Ley 5911» aunque este dato y los antecedentes son equívocos: «Guerrillero detenido hace varias semanas. Desconocido el paradero, según datos apareció muerto y quemado. Peligroso activista e instigador». ${ }^{48} \mathrm{Al}$ parecer, lo confundían, por su apodo «Marcel», con Marcelo Enrique Escobar, estudiante secuestrado en su domicilio el 25/ $3 / 76$ y ejecutado en la vía pública el $07 / 05 / 76 .{ }^{49}$

Tal como destaca Brossat (2006) se trata de «Desapariciones organizadas de enemigos, de opositores políticos o de presuntos opositores, pero también, no lo olvidemos, de individuos o de grupos identificados por sus perpetradores como culpables objetivos, y también, como cuerpos destinados a desaparecer por el simple hecho de su origen considerado indebido...» (p.130).

La inclusión del Estatuto (5719) en este documento refiriendo las causales previstas para el «alejamiento forzoso» del agente de la administración pública (art. 16) fue para señalar que se seguiría el procedimiento fijado en dicha ley. Esas causales, salvo renuncia, incompatibilidad y fallecimiento son casi redundantes tanto con otros artículos de la misma como con la 5913.

Cabe acotar que los Recursos de Reconsideración por los despidos y la quita de indemnización por aplicación de las leyes 5911 y 5913 y sus procedimientos involucraban para su resolución a la Fiscalía de Estado, el Ministerio de Gobierno, la Secretaría de Estado de Seguridad y el PE. ${ }^{50}$ Entre 1976 y 1978 varios empleados dados de baja presentaron recursos, la mayoría en 1976 aunque recién se resolvieron en 1977 y 1978 mediante decretos de rechazo (246 y 198 respectivamente) siendo excepcionales las respuestas favorables.

Otro documento secreto, destinado a establecer en el orden provincial las pautas fijadas por la directiva $N^{\circ}$ 2/77 del Ministerio del Interior para «la organización del Sistema de Comunicación Social para la lucha contra la Subversión en apoyo de la Acción del Gobierno» ${ }^{51}$ señalaba como «situación» que la estrategia nacional antisubversiva se apoyaba en tres pilares fundamentales: 1) la acción de gobierno, para restar adeptos

\footnotetext{
${ }^{48}$ Carpeta SIDE, Casos 40-41_0151

${ }^{49}$ Cf. Romano (2017 a y b).

${ }^{50}$ AGPC, Resolución 347, septiembre 1976.

${ }^{51}$ AGPC, Resolución Secreta N ${ }^{\circ}$ 130, 21/7/77.
} 
a la subversión; 2) la acción militar, cuya finalidad principal es «el aniquilamiento de las organizaciones subversivas» y el apoyo a la acción de gobierno; 3) la acción sicológica, elemento de gravitación en la lucha contra la subversión. El Sistema, se presenta altamente centralizado siendo su máximo responsable el Ministerio del Interior, correspondiendo a la Jefatura del Área 311 (Comando del III Cuerpo de Ejército, comisarías, destacamentos, centros de detención, etc. de la provincia de Córdoba) la responsabilidad de la comunicación social (CS) para apoyar las operaciones militares que se realicen contra la subversión, mientras la CS para apoyar la acción de gobierno (AG) sería responsabilidad del gobierno de Córdoba, en su jurisdicción. La jefatura del Área 311 tendría la misión de organizar «un Elemento de Comunicación Social contra la Subversión en su jurisdicción para apoyar la persecución y completar el aniquilamiento de la delincuencia subversiva» y el gobierno de la provincia apoyaría con la CS «las operaciones realizadas por el Área 311 contra la delincuencia subversiva», además de planear, dirigir, ejecutar, controlar y evaluar la CS para apoyar su propia acción de gobierno. Consignaba también que la CS que desarrollen los medios estructurados a tal fin deberá ser «eminentemente ofensiva».

El Sistema es expuesto seguidamente en un intrincado organigrama de ministerios, secretarías, organismos, funcionarios, funciones, misiones, responsabilidades y recursos para la ejecución del plan de CS. Cabe destacar que entre las misiones de la Secretaría de Estado de Seguridad del gobierno provincial se encuentra la de «coordinación con la autoridad militar (Área 311.-Cdo. Cpo. Ej. III) para lo que implementará un canal técnico ágil y permanente.»Asimismo, en las instrucciones de coordinación se advierte que «toda la documentación que se origine con motivo de la presente directiva tendrá el carácter de 'SECRETO'.»

El documento y cada una de las acciones previstas dan cuenta del perfil ideológico de la dictadura y de la creencia en la «positividad» de las mismas. Al mismo tiempo muestra una estructura organizada al detalle del dispositivo para la coordinación y la cooperación estrecha entre el gobierno de facto de la provincia, el Comando del III Cuerpo de Ejército, otras fuerzas armadas, de seguridad y las de inteligencia de cada sector. Esto quedó plasmado en un gráfico puntillosamente diseñado, que por motivos de espacio no es posible incluir aquí. ${ }^{52}$

52 Tenemos en preparación la publicación completa del documento junto con otros de carácter secreto que relevamos. 


\section{Conclusiones}

El análisis efectuado permite ratificar en buena medida las conclusiones obtenidas en nuestro trabajo anterior sobre la compleja e intrincada trama de dispositivos legales, muchas veces superpuestos, que extendió sus alcances a todos los ámbitos del empleo público a sancionar, especialmente después del golpe de Estado del '76; así como la que expandió las prácticas burocráticas aun cuando se trató de «operaciones» secretas para reprimir a activistas y disidentes políticos.

Y, como planteábamos en 2018,

Las prácticas burocráticas dejaron huellas indelebles acerca de la gestión de las intervenciones federales y del régimen de facto instaurado el 24 de marzo de 1976. Todas las leyes, decretos y resoluciones fueron prolijamente protocolizados, publicados y/o comunicados y archivados (...) Asimismo, como dimos cuenta a lo largo del texto, los argumentos para las sanciones se sustentaron en general en la normativa vigente y, cuando correspondía, en dictámenes del asesor legal, adoptando como naturales prácticas burocráticas «preexistentes», propias del ámbito de la administración pública provincial. Esto fue así, aun cuando se trataba de implementar medidas arbitrarias y de «facto», es decir de dispositivos elaborados y adoptados por un régimen militar que había usurpado el poder por la fuerza arrogándose un poder constituyente, por encima de la Constitución Nacional, a los fines de la persecución política e ideológica de los opositores al régimen, en nuestro caso de empleados y gremialistas de la administración pública de Córdoba (pp.77-78)

El crecimiento exponencial de la producción de decretos en 1976 con respecto al período 1974-75 al que entonces hacíamos referencia como un afán burocrático-administrativo siguió incrementándose hasta casi duplicarlo tanto en 1977 como en 1978. Pensamos al respecto que también les movía el afán de auto legitimación de sus actuaciones revistiéndolas de «legalidad» así como el propósito de reformar el aparato estatal en línea con su proyecto político ideológico totalitario. Aun tratándose de documentos secretos, que por propia disposición del régimen no podían ser publicados, se establecieron procedimientos de esa índole y que culminaban en el archivo.

Pasamos revista aquí a las diversas medidas destinadas a «limpiar» y «depurar» la administración pública de los «subversivos reales o poten- 
ciales» tanto en el período de la intervención federal como en los tres primeros años del PRN. Salta a la vista que aun teniendo en cuenta que la gestión de Lacabanne incrementó significativamente el número de bajas, el volumen de excluidos de la administración se multiplicó diez veces durante los años del Proceso revisados: 352 y 3.161 respectivamente, aunque resulta difícil mensurar su impacto sobre el total de empleados en tanto que año a año se fue incrementando el personal de planta. ${ }^{53}$ Esto mismo muestra que el argumento de la «racionalización» fue la excusa para expulsar a los disidentes.

Cabe destacar en ese marco, las numerosas cesantías por abandono del cargo y por faltas injustificadas, así como por renuncias rechazadas. En relación a ello no deja de ser llamativa la cantidad de renuncias «por razones particulares» que se registran en ambos sub períodos (cf. Gráfico). Como hemos señalado, una buena parte precedía o era inmediato posterior a los cambios de autoridades y de situación política, y en muchos casos fueron presentadas tras culminar licencias prolongadas, también solicitadas por motivos particulares. Al producirse el decreto de aceptación -que es el documento con el que contamos- observamos que en diversos casos habían transcurrido meses e incluso años desde su presentación, principalmente durante el PRN. El total de 2.105 renuncias durante el sub período 1974-75 y de 6.558 para el de 1976-78, no solo pone de manifiesto la importancia numérica de las mismas -superando a los despidos sobre la planta permanente- y su continuidad en el tiempo, sino también su importancia como estrategia de supervivencia de los renunciantes ante un ambiente laboral hostil y represivo signado por los controles, la persecución ideológico política enmarcados en y complementarios de un contexto provincial y nacional de terror paraestatal y estatal, atravesado por secuestros, desapariciones y asesinatos. $\mathrm{Y}$ aun cuando una parte de las renuncias pudiera explicarse por los bajos salarios o bien como el cese en algunos cargos y no de todos, como en la docencia, pensamos que lo que predominó frente al hostigamiento y el terror fue una «cultura del miedo».

\footnotetext{
${ }^{53}$ Si tomamos en cuenta los 42.549 empleados de planta consignados en el presupuesto aprobado en enero de 1974, para febrero del 76 esos despidos representaron menos del 1 $\%$ del total. En ese lapso la planta creció a 46.238 y continuó aumentando hasta 53.507 hasta comienzos de 1979. Considerando la cifra inicial de 1976, la merma representó casi el $7 \%$ de la planta; en tanto que con respecto a la cifra de 1979 el impacto fue del 6\%. BO, Leyes de Presupuesto 5704, 5900 y 6288.
} 
Los documentos secretos comentados, que se suman a otras pistas, dejan al descubierto la intencionalidad punitiva de algunas de las principales normas empleadas y dictadas por el régimen de facto en Córdoba como la disposición de detener a trabajadores que luego, tras concretarse la misma, serían sancionados con la cesantía oficial y públicamente decretada. Para ello contaban con informes de los servicios de inteligencia, como hemos podido ejemplificar, y los antecedentes reunidos por la Secretaría de Seguridad del Estado y el área de personal, además de lo intercambiado y coordinado en la Comunidad Informativa. Y aunque no es posible afirmar la existencia de una relación directa entre esa tramitación anterior al despido y la efectiva e «inmediata detención» delos agentes en su lugar de trabajo, debido muchas veces a las licencias prolongadas, abandonos del cargo y renuncias previas, sí la facilitaron al disponer de datos personales como domicilio, vínculos, fotos, etc. Asimismo, más que la coexistencia, estos documentos desnudan la estrecha y activa relación de cooperación entre el gobierno de facto y las fuerzas represivas y de inteligencia. Como si fueran trama y urdimbre de un mismo tejido para llevar adelante la mentada lucha contra la subversión, presentada en la normativa bajo un manto de legalidad, eficiencia y racionalización de la administración pública de Córdoba.

\section{Referencias bibliográficas}

Agamben, G. (2006). ¿Qué es un dispositivo? Roma, Italia: Nottetempo. Versión en castellano disponible en http://ayp.unia.es/r08/IMG/ pdf/agamben-dispositivo.pdf

Arriaga, A. E. (2016). Represión sindical y disciplinamiento laboral: la violencia en el dispositivo de control del conflicto en EPEC (19731978). En. A. C. Solís y P. Ponza (comps.) Córdoba a 40 años del Golpe. Estudios de la Dictadura en clave local. Córdoba, Argentina: Facultad de Filosofía y Humanidades.

Bohoslavsky, E. y Soprano, G. (ed.), (2010). Un Estado con rostro humano. Funcionarios e instituciones estatales en Argentina (desde 1880 basta la actualidad). Buenos Aires, Argentina: Universidad Nacional de General Sarmiento/Prometeo.

Bourdieu, P. (2015). Sobre el Estado. Cursos en el Collège de France (19891992). Barcelona, España: Anagrama. 
Brennan, J. (1996). El Cordobazo. Las guerras obreras en Córdoba 19551976. Buenos Aires, Argentina: Sudamericana.

Brennan, J. y Gordillo, M. (2008), Córdoba rebelde. El Cordobazo, el clasismo y la movilización social. Buenos Aires, Argentina: De la campana.

Brossat A. (2006). Es testigo, el historiador y el juez. En N. Richard (ed), pp. 123-134. Santiago, Chile: Cuarto Propio.

Bufano, S. y Teixidó, L. (2015). Perón y la Triple A. Las 20 advertencias a Montoneros. Buenos Aires, Argentina: Sudamericana.

Corradi, J. (1996). El método de destrucción. El terror en la Argentina. En H. Quiroga, y C. Tcach (comps.). A veinte años del Golpe. Con memoria democrática. Rosario, Argentina: Homo Sapiens.

Crespo, V. (2007). Legalidad y dictadura. En C. Lida, H. Crespo y P. Yankelevich (comps.). Argentina, 1976. Estudios en torno al golpe de Estado. México, México: FCE/El Colegio de México.

Derrida, J. (1996). Fuevza de ley. El «fundamento mistico de la autoridad». Madrid, España:Tecnos.

Di Liscia, S. y Soprano, G. (eds.). (2017). Burocracias estatales. Problemas, enfoques y estudios de caso en la Argentina (entre fines del siglo $X I X$ y $X X)$. Rosario, Argentina: Prohistoria/UNLPam.

Franco, M. (2012). Un enemigo para la nación. Orden interno, violencia y «subversión», 1973-1976. Buenos Aires, Argentina: Fondo de Cultura Económica.

García Falno, L. (2011). ¿Qué es un dispositivo?: Foucault, Deleuze, Agamben. Aparte Rei (74), Revista de Filosofía disponible en http:/ /serbal.pntic.mec.es/ cmunozl 1/fanlo74.pdf

Groisman, E. I. (1984). El 'Proceso de Reorganización Nacional' y el sistema jurídico. En O. Oszlak (comp.). «Proceso», crisis y transición democrática/1. Buenos Aires, Argentina: CEAL.

Informe de la comisión nacional sobre desaparición de personas (Conadep) Delegación Córdoba. (2007). Córdoba, Argentina: Municipalidad de Córdoba.

Lvovich, D. (2017). Palabras de cierre al dossier: Estudios sobre Ministerios. Actores, políticas y problemas de abordaje entre el primer peronismo y la última dictadura. Estudios Sociales del Estado,3 (6). Megacausa «La Perla». Informe sobre el Juicio al terrorismo de Estado en 
Córdoba. (2012). Córdoba, Argentina: Comisión Provincial de la Memoria/Archivo Provincial de la Memoria.

Oszlak, O. (2006). Burocracia estatal: política y políticas públicas. POSTData Revista de Reflexión y Análisis Politico, XI.

Ortiz, M.L. (2019). Memorias resignificadas del terrorismo de estado en Argentina. El papel de la clase obrera en la represión y la resistencia. Historia Actual Online, 49 (1), 139-150.

Ortiz, M.L. (2014), Córdoba y sus vaivenes.Transformaciones coyunturales y continuidades estructurales en la relación entre Estado, empresarios y mundo obrero (1969-1976). Estudios, (32), 149-167

Paiaro, M. (2014). La forma legal de lo ilegal. La legislación represiva nacional y su incidencia en la provincia de Córdoba (1973-1976). 2PolHis, (12), 99-117.

Palermo, S. y Silva, J. (2016). Expertos, burocracias y política de masas en Argentina. Estudios Sociales del Estado, 2, (3).

Peña, G. A. (2000). SEP: 50 años de historia. Córdoba, Argentina: Sindicato de Empleados Públicos/Agencia Córdoba Cultura.

Pittaluga, R. (2006). La memoria según Trelew. Sociobistórica, (19).

Ponisio, M. (2016). Las leyes de prescindibilidad en los gobiernos locales de la provincia de Santa Fe durante la última dictadura (19761983). Antecedentes y particularidades en su aplicación a partir de un estudio de caso. Revista de Historia, (17).

Quiroga, H. (1994). El tiempo del «Proceso». Conflictos y coincidencias entre politicos y militares. 1976-1983. Rosario, Argentina: Fundación Ross.

Romano, S. (2007). Detrás de la pantalla: autoritarismo, censura y represión en los medios. Un estudio de caso, Córdoba 1973-1983. Prohistoria, XI (11).

Romano, S., San Nicolás, N., Palacios, M. O. y González Lanfir, M. (2010). Vidas y ausencias. Destinatarios de la represión, Córdoba 1969-1983. Córdoba, Argentina: UNC/Archivo Nacional de la Memoria.

Romano, S. (comp.). (2017a [2013]). Historias recientes de Córdoba. Politica y derechos humanos en la segunda mitad del siglo XX. Córdoba, Argentina: Facultad de Filosofía y Humanidades.

Romano, S. (ed.), (2017b [2016]). Colectivos y parcialidades politicas y sociales: los desaparecidos y asesinados de Córdoba en los '70. Córdoba, Argentina: Facultad de Filosofía y Humanidades. 
Romano, S. (2018). Prácticas burocráticas en contextos autoritarios: represión y disciplinamiento en la Administración Pública de Córdoba, 1974-1978. Cuadernos de Historia. Serie economía y sociedad , (20), 47-88.

San Nicolás, N. (2016). Aniquilar la oposición. El terrorismo de Estado en la UNC: contexto y expresiones. En S. Romano (ed.). Colectivos y parcialidades politicas y sociales: los desaparecidos y asesinados de Córdoba en los '70. Córdoba, Argentina: Facultad de Filosofía y Humanidades.

Servetto, A. (2010). 73/76 el gobierno peronista contra las «provincias montoneras». Buenos Aires, Argentina: Siglo XXI.

Servetto, A. (1998). De la Córdoba combativa a la Córdoba militarizada, 1973-1976. Córdoba, Argentina: Ferreyra. 


\section{Nómina de personas desaparecidas y asesinadas en los se- tenta que pertenecieron a la administración pública provin- cial entre 1973 y 1978 (según decretos y resoluciones de gobierno de la provincia de Córdoba)}

Abdón Yacci de Maggi, Mirta Noemí; Agüero Pérez, Fernando Félix; Araujo Herrera, Eduardo César; Araujo Herrera, Héctor Antonio; Arzani de Capella, Juana María del Valle; Avendaño Ríos, Roque Onésimo; Boscarol Capello, José Luis; Brocca Llabres de Herrero, Julia Angélica; Brollo Cozza, Ivar Eduardo; Burns Gullo, Guillermo Tomás; Bustos Benavides, Edelmiro Cruz (h); Cappelli Zeballos, Mónica Marta María; Capuano Verde Villagra, Carlos Alberto; Carreño Flores, Enrique Oscar; Castillo Carranza, Mauricia Zulima; Córdoba Filippi, César Gerónimo; Díaz Rodríguez, Florencio; Ehrenfeld Lenkienickz, Claudio; Escobar Argañaraz, Carlos Alfredo; Fessia Soldano, Carlos Alberto; Fonseca de Pérez, Gloria Nélida; Ghisolfi Poggi, Héctor Hugo; Goyochea Escudero, José Luis; Guzmán Saravia, Marcela Josefina; Heinz Sainz, Ana María del Valle; Landaburu Zabaleta, Elsa Alicia; Landaburu Zabaleta de Catnich, Leonor Rosario; Lanuscou Cavagliano, Roberto Francisco; Lauge Villa, Héctor Oscar; López Sánchez, Hipólito Atilio*; Manzanelli Oliva, Jorge Alberto; Manzanelli Oliva, Juan Carlos; Marchi Bena, Ángel Dante; Melani Bontempo, Norma Hilda; Monasterio Bonomelli, Susana María; Moyano Barrenechea, Aristóbulo Daniel; Mozé Susa, Miguel Ángel; NadraAquin, Jorge Raúl; Navarro Iriarte, Elba Rosa; Ocampo Serra, Rosa Elena; Ochoa Díaz, Hugo Estanislao; Ochoa Mamondes, Pablo Eduardo; Oria Ponte, Elber Mario Hugo; Paulone Stechina, Martha Cecilia; Pereyra Parra, Carlos Alberto; Pérez Pereyra, Jorge Albino; Privitera Pitrella, Salvador; Requena Leyría, Eduardo Raúl; Rioja García, Héctor Adrián; Roque Ousset, Daniel Alberto; Stiefkens de Anquín, Ana María; Talbot Wright Miravet, Héctor Eugenio; Vaca Narvaja Yofre, Miguel Hugo (h)*; Vallejo Recchia, Cristina Elena; Valverde Suárez, Eduardo Jorge*; Varas Aciar, Juan José*; Vera Páez de Rodríguez, Edith; Verdura Zulatto, Beatriz Virginia; Yornet Morchio, Roberto Julio.

Fuentes: Romano: 2016 y 2017; AHPC-AGPC; Decretos y Resoluciones 1973-1980.

* Indica su condición de funcionario. En el caso de Juan José Varas, se incluye «baja por fallecimiento» de su actividad docente en el nivel medio. 